\title{
Assessment of ecological health of Baiyangdian lake in China using ecological health index
}

\author{
Amit Kumar, Saurabh Mishra* and M. P. Sharma \\ (Uttarakhand), INDIA \\ *Corresponding author. E-mail: saurabhmishra20057@gmail.com \\ Received: March 14, 2015; Revised received: July 4, 2015; Accepted: November 22, 2015
}

Biomass and Ecosystem Lab, Alternate Hydro Energy Centre, Indian Institute of Technology Roorkee- 247667,

\begin{abstract}
An effective assessment of ecological health in aquatic ecosystems has become an important issue for researchers, policy-maker and environmentalist globally. The potential of thermodynamic oriented ecological indicators such as eco-exergy (Ex), structural eco-exergy (Ex $x_{\text {st }}$, phytoplankton biomass (BA), and zooplankton biomass $(Z A)$ in ecological assessment and management were used to calculate the ecological health and then correlated individually as well as multiply of Baiyangdian Lake located in the China. To establish a relationship between sub$\mathrm{EHI}$ values of indicators to the overall $\mathrm{EHI}$, data on thermodynamic indicators of the Baiyangdian lake were calculated from literature. The result indicates the ecological health of Baiyangdian lake is coming under the middle categories i.e. $\mathrm{EHI}=40-60$. A deeper analysis of the relationship between the thermodynamic parameters and $\mathrm{EHI}$ using mini tab software and the multiple regression revealed that the $R^{2}>0.9$ for Baiyangdian Lake indicates that these correlations could be tentatively used to predict the ecological health of the Baiyangdian Lake in the future.
\end{abstract}

Keywords: Correlation, Eco-exergy, Ecological health, Phytoplankton, Zooplankton

\section{INTRODUCTION}

The concept of ecosystem health that set new goals for ecological assessment and management emerged in the 1980 s, numbers of attempt have been made to assess lake ecosystem health (Xu and Tao, 2000; Zhang et al., 2010). Several ecological indicators have been proposed for the lake ecosystem health assessment, such as indicators of single sensitive species (Munawar et al., 1994; Lyons et al., 2000), gross ecosystem product (Hannon, 1985), ecosystem stress indicators (Rapport et al., 1985), eco-exergy (Ex) and structural ecoexergy $\left(\mathrm{Ex}_{\mathrm{st}}\right)$ (Jorgensen, 1995a, b), out of these thermodynamic indicators (Ex and Exst) were the most useful ones for the lake ecosystem health assessment in recent decades (Xu et al., 2005). A set of ecological indicators, including structural, functional, and systemlevel aspects were proposed for a lake ecosystem health assessment, according to the structural, functional, and system-level responses of lake ecosystems to chemical stresses, including acidification, eutrophication, and copper, oil and pesticide contamination (Xu et al., 2001). An ecosystem can be defined as an irreducible and self-organizing system. The system cannot be analyzed by simple experiment since; it involves too many components which play an important role in maintaining the ecological balance. It can be explained by heterogeneity of spatial and temporal distribution of its components (Wiegand et al., 2010). Ecosystem health is described as a systemic diagnostic method to evaluate the ecosystem characteristics associated with human health under the framework of ecology. A healthy ecosystem has been referred as stable and sustainable ecosystem, maintaining its organization and autonomy over time and its resilience to various stresses. As a complex ecosystem, Baiyangdian lake ecological health, in China, can be well assessed by using thermodynamic indicators like BA, BZ, Ex, and $\mathrm{Ex}_{\mathrm{st}}$. Exergy is explained as the amount of work a system can perform at thermodynamic equilibrium within its environment, while Exst or specific exergy is the exergy calculated relative to the total biomass. These indicators seem to be the most useful ones in assessing lake ecological health in recent decades. Phytoplanktons are the main primary producers in lakes and Lake Eutrophication which induce excessive increases in producer productivity and biomass (Xu et al., 2013). The phytoplankton and zooplanktons directly influences the water quality and functions as an important biological index in many Asian countries to estimate the ecological status of lakes. Being in the pristine part, the Baiyangdian Lake is under assault by various industrial waste, domestic waste, etc. The lake has become a site of waste disposal containing toxic waste has degraded the water quality of this lake $(\mathrm{Xu}$ et al., 2012). Therefore, in order to assess the ecological of this lake, the present paper reports the results of developing the correlations for the Baiyangdian Lake, located in Hebei Province, China, based on biotic and thermodynamic indicators and reservoir characteris- 
tics. Beside this, linear and multiple correlation was also developed to predict lake health in the future as well.

\section{MATERIALS AND METHODS}

Study site: The Baiyangdian Lake, which is the largest natural lake in Hebei Province, China, called as "kidney" of northern China, located at coordinate of $115^{\circ} 45^{\prime}-116^{\circ} 07^{\prime} \mathrm{E}$ and $38^{\circ} 43^{\prime}-39^{\circ} 02^{\prime} \mathrm{N}$. In spring, clear fresh water with fresh green reed; at a distance mists and ripples stretch. In summer, the lotus and water caltrop are found. In autumn, fishing is done, fishes and crabs as an economic source to the people surrounding this lake. In winter, the lake freezes and the snow falls can be seen. At present, Baiyangdian Lake was seriously eutrophied with different impaired conditions in water under a variety of disturbances, resulting in severe negative effects on the ecological health, sustainable development and management (Xu et al., 2011). The salient features are given in Table 1 and the sampling locations have been given in Fig.1.

Calculation of ecological health index (EHI): The EHI methodology was applied to assess the health status of Baiyangdian Lake in China (Xu et al., 2005). By using the sub-EHI calculations for each indicator, the corresponding values for all indicators relative to the numerical EHI can be obtained. The EHI has been calculated by following equations:

$$
\begin{aligned}
& \text { Sub EHI }=10\left(a+b \ln C_{x}\right) \\
& a=-10 \times \frac{\ln C_{x}}{\ln C_{\max }-\ln C_{\min }} \\
& b=10 \times \frac{1}{\ln C_{\max }-\ln C_{\min }} \\
& w_{i}=\frac{r_{i 1}^{2}}{\sum_{i=1}^{m} r_{11}^{2}}
\end{aligned}
$$

\begin{tabular}{|c|c|c|}
\hline S.N. & Feature & Data \\
\hline 1. & Location & Hebei Province, China \\
\hline 2. & Elevation & $8.2 \mathrm{~m}$ \\
\hline 3. & Altitude & $13406.94 \mathrm{~m}$ \\
\hline 4. & Water depth & Between 5.2 and $9.26 \mathrm{~m}$ \\
\hline 5. & Water level & Below 6.5 and $5.5 \mathrm{~m}$ \\
\hline 6. & Catchments area & $31200 \mathrm{Km}^{2}$ \\
\hline 7. & Mean surface area & $366 \mathrm{Km}^{2}$ \\
\hline \multicolumn{3}{|c|}{ Table 2. Health status range characterization. } \\
\hline & Range & Health status \\
\hline & $0-20$ & Worst \\
\hline & $20-40$ & $\mathrm{Bad}$ \\
\hline & $40-60$ & Middle \\
\hline & $60-80$ & Good \\
\hline & $80-100$ & Best \\
\hline
\end{tabular}

Table 1. Salient features of the Baiyangdian Lake.

$$
\text { EHI }=\sum_{i=1}^{n} w_{i} \times \text { SUB E HI }
$$

Where; Sub-EHI includes (BA or BZ or Ex or Exst), $\mathrm{C}_{\mathrm{x}}$ is the measured indicator value; $\mathrm{C}_{\max }$ is the measured maximum value when Sub-EHI is $0 ; \mathrm{C}_{\min }$ is the measured value when the measured sub EHI is 100; ' $a$ ' and ' $b$ ' are constants evaluated by $\mathrm{C}_{\min }$ and $\mathrm{C}_{\max }, \mathrm{w}_{\mathrm{i}}$ is the weightage factor for $i^{\text {th }}$ indicator; $r_{i 1}$ is the correlation ratio between the $\mathrm{i}^{\text {th }}$ indicators and basic indicator; $\mathrm{m}$ is the total no. of indicator considered. The EHI range to define the health status of lake is 0-100; zero indicates the worst possible health state and 100 indicates the best possible health state as show in Table 2:

Data collection and analysis: Since the river health data availability is very much scarce, the phytoplankton, zooplankton, $\mathrm{Ex}$ and $\mathrm{Ex}_{\mathrm{st}}$ data of Baiyangdian Lake were extracted from the literature ( $\mathrm{Xu}$ et al., 2012) and converted in to a sub EHI index (EHI-BA, EHI-BZ, Ex and $\mathrm{Ex}_{\text {st }}$ ) to calculate the overall ecological health of the Baiyangdian Lake as shown in Table 3. The data of phytoplankton, zooplankton, Ex and structural exo-exergy of the year 2012 was collected from 14 lake sites from the literature (Xu et al., 2012). The ecological health data from the Baiyangdian Lake was analyzed with respect to EHI-BA, EHI-BZ, Ex, and $\mathrm{Ex}_{\mathrm{st}}$ in order to develop relationships using Mini Tab software. Linear relation of ecological health with biological parameters has been shown in Table 4 and Fig. 3.

From the above Fig. 2, it can be observed that the value of $\mathrm{R}^{2}$ in three cases (EHI-BZ, Ex and $\mathrm{Ex}_{\mathrm{st}}$ ) is insignificant and so these cannot be used to assess the impact of individual parameters of ecological health, but rest two (EHI-BA) might be used to impacting the ecological health. An empirical equation involving all the parameters of Ecological health is found as:

$\mathrm{EHI}=-7.55+0.802 \mathrm{EHI}-\mathrm{BA}+0.114 \mathrm{EHI}-\mathrm{BZ}+$ $0.201 \mathrm{Ex}+0.285 \mathrm{Ex}_{\mathrm{st}} \ldots \ldots \ldots \ldots \mathrm{R}^{2}=0.989$.

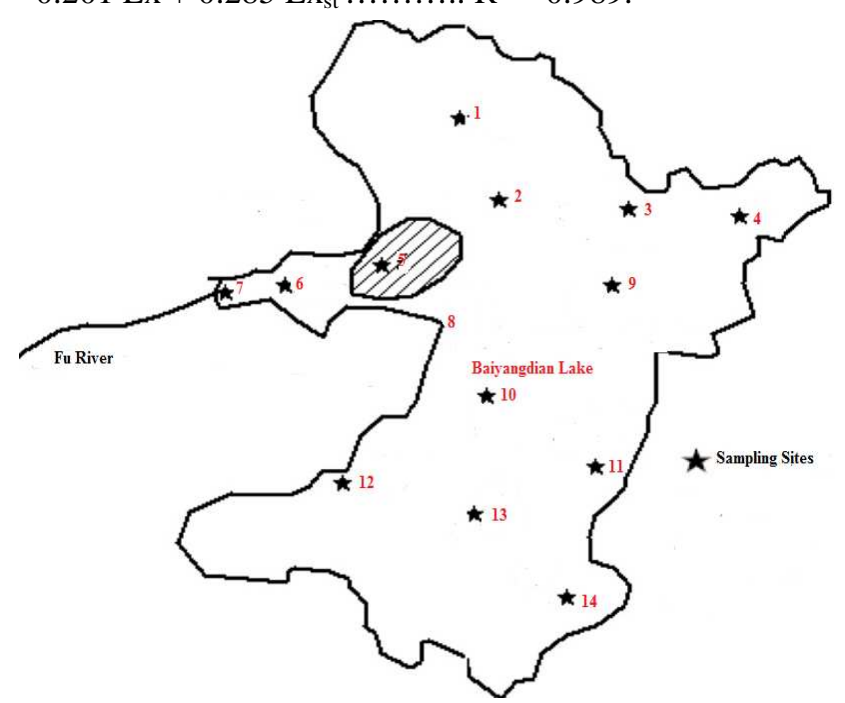

Fig. 1. Schematic diagram of Baiyangdian Lake (Xu et al., 2011). 
Table 3. Determination of ecological health index of Baiyangdian Lake, 2012.

\begin{tabular}{clllllll}
\hline $\begin{array}{c}\text { Sampling } \\
\text { Sites }\end{array}$ & $\begin{array}{l}\text { EHI } \\
(\mathbf{B A})\end{array}$ & $\begin{array}{l}\text { EHI } \\
\mathbf{( B Z )}\end{array}$ & $\mathbf{E H I}(\mathbf{B Z / B A})$ & $\mathbf{E H I}(\mathbf{E x})$ & $\mathbf{E H I}\left(\mathbf{E x}_{\mathbf{s t}}\right)$ & EHI & Health status \\
\hline 1 & 33.37 & 96.94 & 96.28 & 99.99 & 19.44 & 55.01 & Middle \\
2 & 58.80 & 83.63 & 56.85 & 06.00 & 08.40 & 55.09 & Middle \\
3 & 64.91 & 81.17 & 48.22 & 04.93 & 07.77 & 56.49 & Middle \\
4 & 00.00 & 72.84 & 99.99 & 61.14 & 99.99 & 41.00 & Middle \\
5 & 76.67 & 83.74 & 40.08 & 00.00 & 03.96 & 61.39 & Good \\
6 & 23.98 & 18.78 & 14.79 & 27.27 & 02.04 & 19.42 & Worst \\
7 & 16.65 & 01.12 & 0 & 24.03 & 0.09 & 09.98 & Worst \\
8 & 57.95 & 90.31 & 65.37 & 19.67 & 13.99 & 58.21 & Middle \\
9 & 45.84 & 91.40 & 78.07 & 40.25 & 17.64 & 55.12 & Middle \\
10 & 61.52 & 89.02 & 60.49 & 06.00 & 11.52 & 58.28 & Middle \\
11 & 79.55 & 90.95 & 45.70 & 03.79 & 05.24 & 65.31 & Middle \\
12 & 99.91 & 09.99 & 36.90 & 00.00 & 03.32 & 76.10 & Good \\
13 & 49.28 & 88.09 & 70.99 & 36.62 & 15.82 & 54.99 & Middle \\
14 & 04.71 & 75.17 & 98.19 & 60.08 & 89.70 & 42.44 & Middle \\
\end{tabular}

Table 4. Linear relation of ecological health with biological parameters.

\begin{tabular}{clll}
\hline S. $\mathbf{N}$. & Biological parameters & Equations & $\mathbf{R}^{2}$ \\
\hline 1 & EHI vs. EHI-BA & $\mathrm{y}=0.4656 \mathrm{x}+28.249$ & $0.60^{*}$ \\
2 & EHI vs. EHI-BZ & $\mathrm{y}=0.2794 \mathrm{x}+31.213$ & 0.28 \\
3 & EHI vs. Ex & $\mathrm{y}=-0.1619 \mathrm{x}+55.141$ & 0.07 \\
4 & EHI vs. Ex & $\mathrm{y}=-0.0801 \mathrm{x}+52.344$ & 0.02 \\
\hline
\end{tabular}

*- indicates good regression coefficient $\left(\mathrm{R}^{2}\right)$
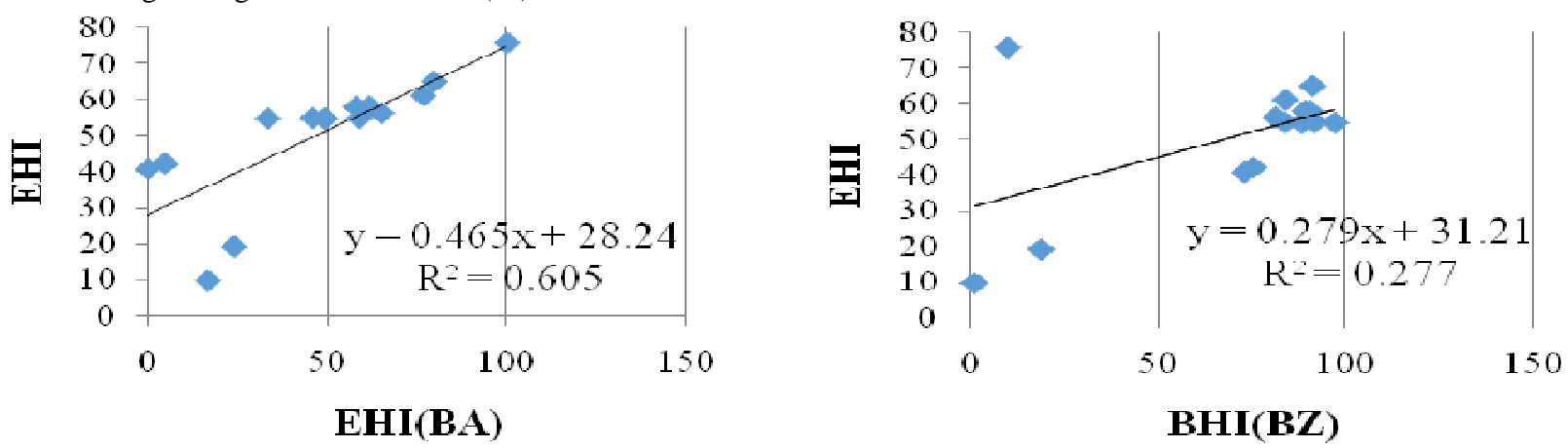

(a)

(c)
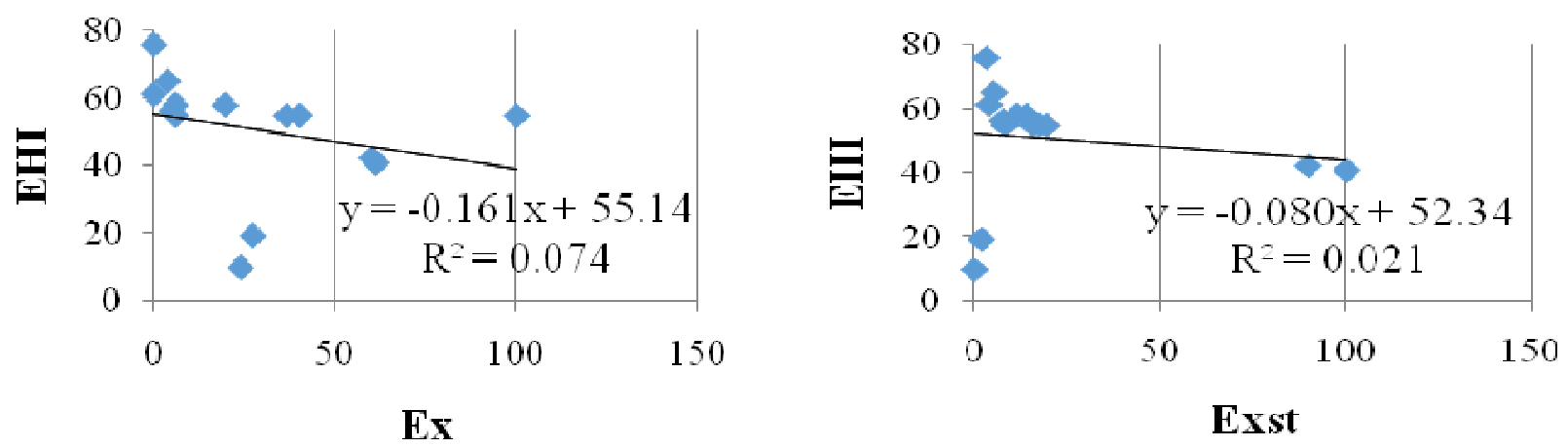

(b)

(d)

Fig. 2. Linear corelation between EHI Vs. (a) EHI (BA) (b) EHI(BZ) (c) Ex \& (d)Exst.

\section{RESULTS AND DISCUSSION}

Overall ecological health index (EHI) was calculated using EA, EZ, Ex and $\mathrm{Ex}_{\mathrm{st}}$, and results found that the ecological health at site 6 and 7 was worst $(\mathrm{EHI}=0-20)$, while at site 5 and 12 was found good $(\mathrm{EHI}=60-80)$ and rest of the site show middle health $(\mathrm{EHI}=40-60)$, whereas overall health of Baiyangdian Lake was found middle, shows very little anthropogenic disturbances in the lake. These regulating measures for health im- 


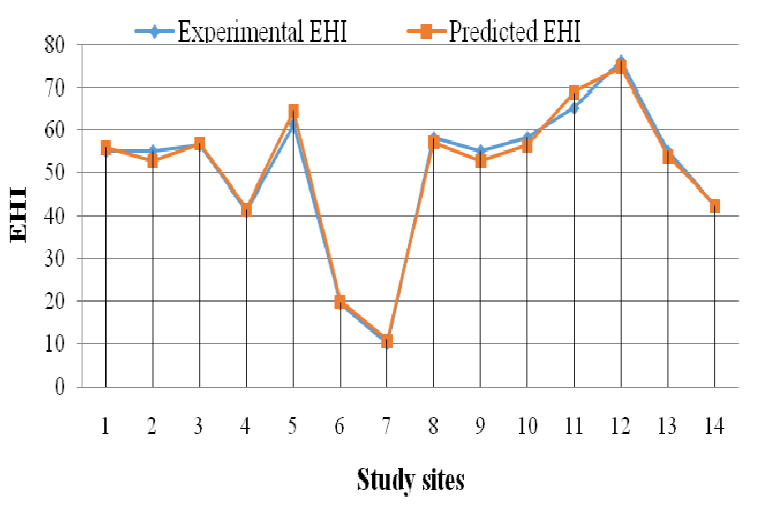

Fig. 3. Comparative analysis and of predicted experimental EHI.

provement are mainly determined by focusing on the nutrient-loading sources of water areas and the submerged plant management of water area. Generally, a healthy ecosystem would be characterized by small cell size phytoplankton, large body size zooplankton, high zooplankton/phytoplankton ratio, high species diversity, high algal $\mathrm{C}$ assimilation, high resource use efficiency, low community production, high exergy, high structural exergy and high buffer capacities (Xu et al., 1999). The impact of the thermodynamic parameters on ecological health from lakes/reservoirs was predicted by (Zhang et al., 2013) showing that the correlation cannot be universally applied to different lake other than the lake under study. These results show that the empirical equation can be used to predict the ecological health of the study site. These results show that health of the lake is mainly affected by phytoplankton and zooplankton. The coefficient of $\mathrm{R}^{2}$ for ecological health with respect to various biological parameters, as given in Table 4, shows that the relatively good correlation of ecological health with phytoplankton $\left(\mathrm{R}^{2}=0.60\right)$, zooplankton (0.28), Ex (0.07) and structural exo-exergy (0.02) of the Baiyangdian Lake has seen. Further, the multiple regression equations are developed between ecological health and all the 4 parameters, as given in Table 5 which yields coefficients of $R^{2}$ as 0.989 of the Baiyangdian Lake. It means that empirical equation based on a large number of parameters can be best used to explain the role of aquatic environment for the ecological health and suitable prediction can be made for the lake in question.

A comparison of predicted and observed ecological health index (Fig. 3) for Baiyangdian Lake has indicated only $\pm 7 \%$ error which shows that these equations can be suitably used for the prediction of ecological health in the Baiyangdian Lake in the future. Xu et al. (2011; 2012) used eco-exergy, structural ecoexergy, the ratio of zooplankton biomass to phytoplankton biomass, and phytoplankton biomass to know the states of health of water areas in Baiyangdian Lake. The results reveal that the water areas at sites 5 and 12 have are in relatively good health, while the health of other areas has deteriorated to varying degrees. Moreover the overall ecological health of lake is comes un- der the categories of moderate. The moderate health of the present study stretch of the Baiyangdian Lake can also be authenticated by the results of published work (Xu et al., 2011; 2012). To bring about the improvement in the lake health, the corrective conservation measures may be appropriately taken by concerned authorities so that lake pollution is reduced in the future.

\section{Conclusion}

Based on the EA, EZ, Ex and Exst, the overall EHI were assessed at 14 sites in Baiyangdian Lake located in China. The results indicated that the BA, BZ, Ex, and $\mathrm{Ex}_{\mathrm{st}}$ are important parameters in assessment of ecological health of Baiyangdian Lake. The result also revealed that the overall lake health comes under the categories of middle class which could be due to little anthropogenic hindrances. A deeper analysis of the relationship between the thermodynamic parameters and EHI using mini tab software and the multiple regression revealed that the $\mathrm{R}^{2}>0.9$ for Baiyangdian lake indicated that these correlations could be tentatively used to predict the ecological health of Baiyangdian Lake in the future.

\section{ACKNOWLEDGEMENT}

One of the authors (SM) is thankful to MHRD, Government of India for financial assistance in the form of academic scholarship during his M.Tech in Environmental Management of rivers and lakes, IIT Roorkee.

\section{REFERENCES}

Hannon, B. (1985). Ecosystem flow analysis. Can. Bull. Fish Aquat. Sci., 213: 97-118.

Jorgensen, S.E. (1995a). Exergy and ecological buffer capacities as measures of ecosystem health. Ecosyst. Health., 1: 150-160.

Jorgensen, S.E. (1995b). The application of ecological indicators to assess the ecological condition of a lake. Lakes Reservoirs: Res. Manage., 1: 177-182.

Lyons, J. Gutierrez-Hernandez, A. Diaz-Pardo, E. SotoGalera, E. Medina-Nava, M. Pineda-Lopez, R. (2000). Development of a preliminary index of biotic integrity (IBI) based on fish assemblages to assess ecosystem condition in the lakes of central Mexico. Hydrobiologia., 418: 57-72.

Munawar, M. Munawar, I.E. Weisse, T. Leppard, G.G. Legner, M. (1994). The significance and future potential of using microbes for assessing ecosystem health: the Great Lakes example. J. Aquat. Ecosyst. Health., 3: 295 -310 .

Rapport, D.J. Regier, H.A. Hutchinson, T.C. (1985). Ecosystem behavior under stress. Am. Naturalist., 125: 617640.

Wiegand, J. Raffaell, D. Smart, C.R. White, P.C.L. (2010). Assessment of temporal trends in ecosystem health using an holistic indicator. J. Environ. Manage., 91:1446-1455.

Xu, F. Jorgensen, S.E. Tao, S. (1999). Ecological indicators for assessing freshwater ecosystem health. Ecol. Model., 116: 77-106. 
Xu, F. Tao, S. Dawson, R.W. Li, P. Cao, J. (2001). Lake Ecosystem Health Assessment: Indicators and Methods. Water Research., 35: 3157-3167.

Xu, F. Yang Z.F. Chen, B. Zhao, Y.W. (2011). Ecosystem health assessment of the plant-dominated Baiyangdian Lake based on eco-exergy. Ecol. Model., 222:201-209.

Xu, F. Yang, Z.F. Chen, B. Zhao Y.W. (2012). Ecosystem Health Assessment of Baiyangdian Lake Based on Thermodynamic Indicators. Procedia Environ. Sci., 8: $2402-2413$.

Xu, F. Yang, Z.F. Chen, B. Zhao Y.W. (2013). Impact of submerged plants on ecosystem health of the plantdominated Baiyangdian Lake, China. Ecol. Model., 252: 167- 175 .
Xu, F.L. Tao, S. (2000). On the study of ecosystem health: the state of the art. J. Environ. Sci., (China) 12: 33-38.

Xu, F.L. Zhao, Z.Y. Zhan, W. Zhao, S.S. Dawson, R.W. Tao, S. (2005). An ecosystem health index methodology (EHIM) for Lake Ecosystem health assessment. Ecol. Model., 188: 327-339.

Zhang, J. Gurkan, Z. Jørgensen, S.E. (2010). Application of eco-exergy for assessment of ecosystem health and development of structurally dynamic models. Ecol. Model., 221: 693-702.

Zhang, L.L. Liu, J.L. Yang, Z.F. Li, Y. Yang, Y. (2013). Integrated ecosystem health assessment of a macrophyte-dominated lake. Ecol. Model., 252: 167175. 